\title{
Fabrication of Wafer-Level Thermocompression Bonds
}

\author{
Christine H. Tsau, S. Mark Spearing, and Martin A. Schmidt, Senior Member, IEEE
}

\begin{abstract}
Thermocompression bonding of gold is a promising technique for achieving low temperature, wafer-level bonding. The fabrication process for wafer bonding at $300{ }^{\circ} \mathrm{C}$ via compressing gold under $7 \mathrm{MPa}$ of pressure is described in detail. One of the issues encountered in the process development was e-beam source spitting, which resulted in micrometer diameter sized Au on the surfaces, and made bonding difficult. The problem was solved by inserting a tungsten liner to the graphite crucible. Surface segregation of $\mathrm{Si}$ on the Au surface at the bonding temperature was observed. Using Auger spectroscopy, a $1500 \AA \mathrm{SiO}_{2}$ barrier layer was shown to be sufficient in preventing $\mathrm{Si}$ from reaching the surface. Lastly, a four-point bend delamination technique was used to quantify the bond toughness. The associated process steps that were required to prepare the test specimens are described. The critical strain energy release rate for the bonds ranged between 22 to $67 \mathrm{~J} / \mathrm{m}^{2}$ and was not shown to be strongly associated with the gold bond layer thickness in the thickness range studied $(0.23$ to $1.4 \mu \mathrm{m})$.

[828]
\end{abstract}

Index Terms-Thermocompression bonding, wafer bonding.

\section{INTRODUCTION}

W ITH devices that operate across multiple energy domains - such as electrical, mechanical, thermal and fluidic-packaging in microelectromechanical systems (MEMS) is complex. A package interfaces with harsh environments while protecting components to maintain device integrity. It is often application specific. With a majority of the devices being produced in low volume, packaging cost can reach more than $70 \%$ of the total cost [1]. Since packaging is frequently a die-level process, the cost may be reduced by packaging at the wafer-level. Not only would the devices be released more economically [2], but the seals would prevent diesaw slurries and other contaminants from entering the device region at the back-end of the process. Moreover, the devices could be capped under desired pressure and ambient. By using conductive material for sealing, electrical feedthroughs could also be incorporated. This adds flexibility in both the device design and upper-level packaging. There are several widely

Manuscript received March 15, 2002; revised July 15, 2002. This work was supported by DARPA (F30602-97-C-0127), SRC (2001-MJ-881), and SRC Graduate Fellowship. Fabrication was carried out at MIT Microsystems Technology Laboratories and tested at MIT Technology Laboratory for Advanced Composites. Subject Editor E. Obermeier.

C. H. Tsau is with Microsystems Technology Laboratories and the Department of Materials Science and Engineering, Massachusetts Institute of Technology, Cambridge, MA 02139 USA (e-mail: chtsau@mtl.mit.edu).

S. M. Spearing is with the Department of Aeronautics and Astronautics, Massachusetts Institute of Technology, Cambridge, MA 02139 USA.

M. A. Schmidt is with Microsystems Technology Laboratories, Department of Electrical Engineering and Computer Science, Massachusetts Institute of Technology, Cambridge, MA 02139 USA.

Digital Object Identifier 10.1109/JMEMS.2002.805214 used techniques available for low temperature wafer-bonding: anodic bonding, solder bonding, and eutectic bonding. Although these techniques can be highly effective, each has some limitations. Induced thermal stress and applied voltage are issues to be considered in anodic bonds. Eutectic or solder bonds are conductive, less susceptible to particulates and more lenient on surface roughness requirements [3]. However, rubbing or brazing of the surface, or the use of a flux or reducing atmosphere, is needed in order to remove oxides. If the process is not well controlled, voids or inhomogeneity will be introduced at the bond interface [4]. An alternative is proposed here: gold thermocompression bonding. This wafer-level, low temperature process will be described in detail along with bond toughness measurements of the resulting bonds to provide a quantitative assessment of the technique.

\section{A. Thermocompression Bonding}

Thermocompression bonding is a form of solid state welding in which the simultaneous application of pressure and heat forms bonds between two otherwise separate surfaces. At room temperature, tremendous pressure is needed for interatomic attraction to overcome surface asperities [5]. Materials tend to soften with increasing temperature. Therefore, the pressure requirement can be offset by increasing the processing temperature. Thermocompression has been a standard packaging technique in microelectronics, in both wire and tape automate bonds. While several materials are bondable under modest temperature and pressure, bonding is easier to achieve in some materials than others. For instance, the oxides that naturally occur on the surface of solders prevent the formation of a strong bond. For successful bonding, these oxides must be removed either chemically or mechanically. Consequently, oxidation resistant materials such as gold are often preferred. The low yield point of pure gold aids the thermocompression process and its corrosion resistance and electrical conductivity are desirable properties for packaging. In addition, gold does not attract inorganic substances such as slurry particles [6]. Lastly, as a metal, gold is expected to be effective as a hermetic sealing material [7].

Thermocompression bonding of gold was first used in wirebonds. Jellison examined the effects of UV-ozone prebonding treatment and post-bonding anneal on bond strength [8]. Condra et al. studied the deformation properties of gold to better understand the thermocompression process [9]. When larger arrays of bonds became desirable, studies on bump-lead bonds began. Kim et al. bonded 328 contacts to tape automated bonding leads and reported pressure and duration as important bonding parameters [10]. All of the studies cited thus far were for die-level 
bonds. True large array bonding of bumps was described by Furman and Mita, where up to 60000 contact pads were bonded on $127 \mathrm{~mm}$ by $127 \mathrm{~mm}$ ceramic substrates using a heated press [11]. The minimum pressure of $0.689 \mathrm{MPa}$ was applied for as long as $3 \mathrm{~h}$, with $1 \mathrm{~h}$ at the peak temperature of either 400 or $375^{\circ} \mathrm{C}$ and a peak pressure that ranged from 0.689 to $2.76 \mathrm{MPa}$. These are the pressures that were applied to the substrate. Since the actual bonding area was some fraction of the bond pads, each $150 \mu \mathrm{m}$ by $450 \mu \mathrm{m}$, the actual bonding pressure on the Au was greater than the peak pressure reported.

Gold bumps for tape automated bonding tend to be thick $(>20$ $\mu \mathrm{m})$. One demonstration of thin film bonding was in the sealing of capacitive pressure sensor dice: approximately $2 \mathrm{MPa}$ of pressure was applied to $1.2 \mu \mathrm{m}$ thick gold at $350^{\circ} \mathrm{C}$ for $2 \mathrm{~min}$ [12]. Very little work has been reported of bonding at the wafer-level. Drost et al. reported a pressure of $0.06 \mathrm{MPa}$ at the wafer-level as insufficient for continuous bond formation: bonds were highly localized and on the micrometer scale [13]. At the chip-level, they bonded $4 \mu \mathrm{m}$ Au films for $1 \mathrm{~min}$ with varying temperatures and pressures to $\mathrm{Au}$, from 350 to $450^{\circ} \mathrm{C}$ and 0.32 to $17.86 \mathrm{MPa}$, respectively. An increase in daisy chain resistor yield was reported for pressures up to $1 \mathrm{MPa}$; further increases in pressure or temperature showed little benefit. However, additional bonding time was found to improve bond homogeneity [13]. The present study investigates wafer-level bonding using the thin-film approach with modest applied temperature and pressure. Although the gold on Si-substrate process will be described, the process is transferable to other substrate materials.

\section{B. Mechanical Testing}

It is important to quantify the bond quality in order to develop and improve the bonding process. Resistance testing is one approach, although in bonds involving conductive materials, resistors could still be measured even though the bonds may not be continuous. Shear or pull tests are another commonly used metric [8], [10]. However, alignment of the grips and flaws along the edges of the specimen (which could occur during dicing) can lead to premature failure, resulting in measurements which do not reflect the output of the bonding process itself [14]. In the wafer bonding community, the double cantilever beam test is frequently used. First described by Maszara et al., this is an easy test to perform in which the insertion of a razor blade results in a crack length opening that is measurable in the IR [15]. A surface energy can then be calculated. However, there are several shortcomings with this method. Comparison between research groups is difficult because measurements can be influenced by factors that are often not reported, such as measurement conditions. Humidity is known to affect the observed surface energy considerably [14]. It is often difficult to keep the blade perfectly perpendicular to the interface so that the crack front is straight and parallel to the flat edge of the blade. Most importantly, the surface energy has a fourth order dependence on the measured crack length, leading to large variance in the surface energy from variance in the length measured.

In this study, a four-point bend delamination technique is used to obtain the critical energy release rate, $\mathcal{G}_{c}$, of the bond interface, as described by Charalambides et al. [16]. Crack propagation, or bond failure, occurs only when the critical load associ-

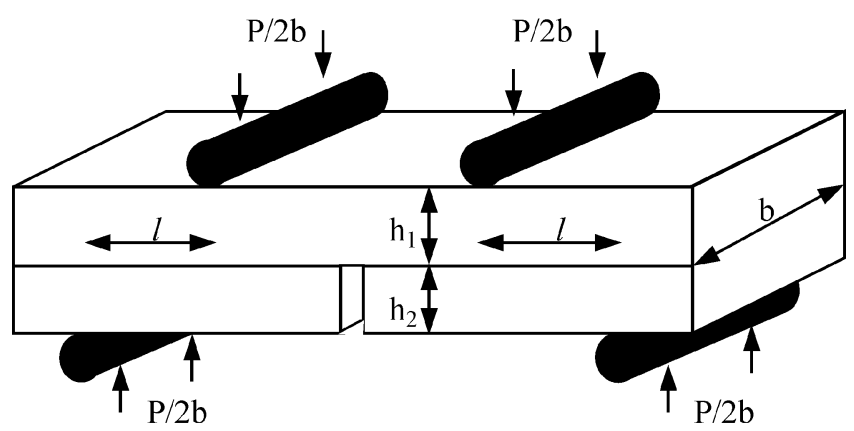

Fig. 1. Illustration of a four-point bend delamination specimen.

ated with $\mathcal{G}_{c}$ is reached. In brittle materials, the toughness is essentially the surface energy. In fractures involving ductile layers, however, additional energy can be dissipated due to plastic work at the crack tip. A typical specimen is shown in Fig. 1. By establishing a constant moment condition for crack propagation due to the four-point loading, the resulting strain energy release rate is independent of crack length [16]. This improves the accuracy of the $\mathcal{G}_{c}$ calculation. The critical energy release rate for this specimen is given by

$$
\mathcal{G}_{c}=\frac{1.5\left(1-\nu^{2}\right)}{E}\left(\frac{P_{c} l}{b}\right)^{2}\left(\frac{1}{h_{1}^{3}}-\frac{1}{\left(h_{1}+h_{2}\right)^{3}}\right)
$$

where $E$ is the Young's modulus, $\nu$ is the Poisson's ratio, $P_{c}$ is the critical load at which crack propagation occurs, $l$ is the distance between the upper and lower rollers, $b$ is the width of the specimen, and $h_{1}$ and $h_{2}$ are the thickness of the unnotched wafer and notched wafer, respectively. Equation (1) shows $\mathcal{G}_{c}$ as functions of the specimen geometry and applied load, both of which can be measured quite accurately.

\section{EXPERIMENTAL PROCEDURE}

Each bonding pair consisted of 4-in n-type Si wafers with average thicknesses of $525 \mu \mathrm{m}$ and $450 \mu \mathrm{m}$, the latter being a double-side polished (DSP) wafer. The notch geometry shown in Fig. 2(a) was formed by $\mathrm{KOH}$ etching a $500 \mu \mathrm{m}$ wide and $60 \mu \mathrm{m}$ deep central trench in the DSP wafer. Next, a $100 \mu \mathrm{m}$ wide, $1 \mu \mathrm{m}$ deep trench was anisotropically dry etched around the perimeter of the central trench. Following thermal oxidation, both wafers were identically patterned with Clariant AZ5214-E image reversal resist. A $10-\mathrm{nm}$ Ti-adhesion layer and 0.1 to 0.7 $\mu \mathrm{m}$ of Au were then e-beam deposited onto both wafers. Lift-off resulted in groups of $50 \mu \mathrm{m}$ by $60 \mathrm{~mm}$ lines. The spacing between lines within each group was $250 \mu \mathrm{m}$. The major process steps and a schematic of the wafers after lift-off are shown in Fig. 2.

To ensure complete removal of organics, wafers were exposed to UV-ozone for $90 \mathrm{~min}$ immediately before wafer alignment. Three triangular separators, about $100-\mu \mathrm{m}$ thick and $1-\mathrm{cm}$ long, were inserted between the wafers at the edges to maintain a vertical separation between wafers until bonding. Bonds were made in an Electronic Visions AB1-PV bonder under a nitrogen atmosphere. Following the temperature ramp and the 3-min stabilization period at $300{ }^{\circ} \mathrm{C}, 0.02 \mathrm{MPa}$ pressure was applied over the wafer and the separators were withdrawn. A 


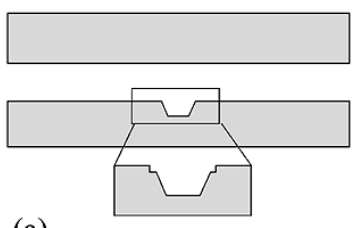

(a)

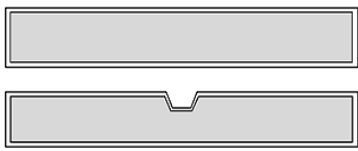

(b)

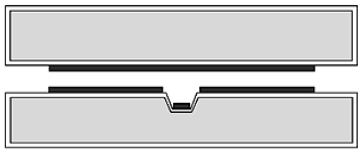

(c)

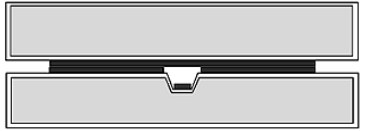

(d)

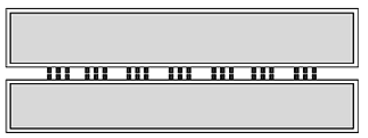

(e)

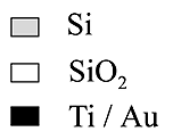

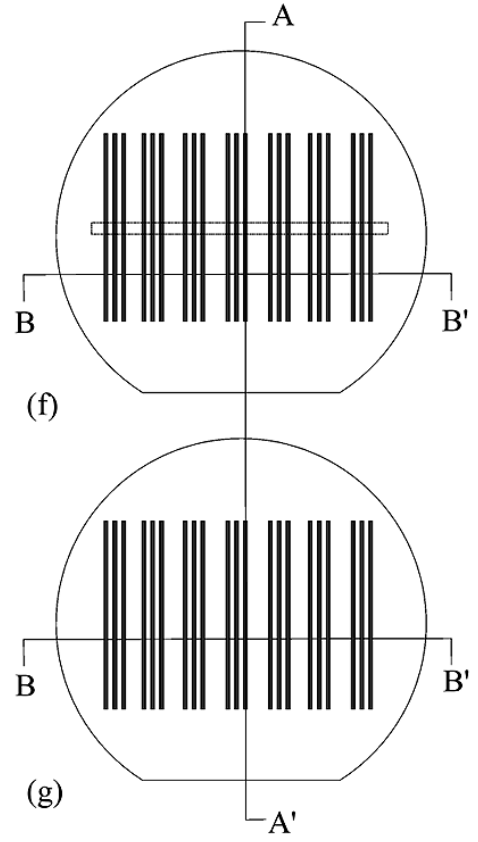

Fig. 2. Schematic of process flow, with cross sections taken along A-A' for (a)-(d), and along B-B' for (e). (a) Bonding pair. Detail shows notch region in DSP wafer (bottom) after KOH and shallow anisotropic etching. (b) Thermal oxidation. (c) Metal deposition. (d), (e) Aligned bonding. (f), (g) Top view of DSP and regular wafers after lift-off, respectively. Dashed central rectangle in (f) indicates the location of the etched trench.

bonding pressure of $0.5 \mathrm{MPa}$ was then applied across the wafer, corresponding to $7 \mathrm{MPa}$ of pressure on the $\mathrm{Au}$, for $10 \mathrm{~min}$. The temperature was subsequently ramped down.

Mechanical test specimens were made by dicing the bonded wafers into $8 \mathrm{~mm}$ wide strips. A width-wise cut was made above the $\mathrm{KOH}$-etched notch to the DSP wafer, exposing the bonded interface. Mechanical tests were performed using a servo-hydraulic mechanical testing machine in its displacement-controlled mode at a rate of $0.15 \mathrm{~mm} / \mathrm{min}$. The specimen rested on the outer rollers, which sat on a fixture that was rigidly attached to the upward moving crosshead. The inner rollers were attached to the stationary portion of the testing machine via an adjustable grip. The adjustable grip improved the positional leveling of the top apparatus. The alignment of the apparatus was checked immediately prior to testing with strain gauges located below the inner rollers. A $100 \mathrm{~N}$ load cell was used to monitor the load. Load and cross-head displacement data were captured by a LabVIEW program while real-time observations of the specimen were made with a long working distance microscope.

After the test was completed, the crack lengths on either side of the $\mathrm{KOH}$-etched notch were noted and a width-wise line was scribed on the surface of the DSP wafer, above the end of each of the cracks. The specimen was then loaded in a 3-point bend jig to promote crack growth from the scribed line to the bond interface, thereby detaching the delaminated segments from the still bonded portion of the specimen. Since minimal force was required for this procedure, any observable deformation reflected those sustained during the four-point bend delamination test. The fracture surfaces were examined using a scanning electron microscope (SEM). The degree of misalignment, 1 to $4 \mu \mathrm{m}$, was measured at $1000 \times$ magnification. Calculations of the bond toughness reported here reflect the actual bonded areas.

\section{RESULTS AND DiSCUSSION}

\section{A. Fabrication Process}

Initially, bonds were made with unoxidized wafers [17]. Discoloration of gold, such as those shown in Fig. 3, was observed on portions of the wafers that failed to bond. Using Auger spectroscopy, the elemental composition in those regions was identified as silicon with varying amounts of oxygen. By sputtering away the surface atoms, it was determined that the oxygen signal came from oxidation of silicon at the surface. Moreover, the signal intensity of the silicon decreased with distance into the gold. Experiments using a Ge substrate indicated that the silicon had originated from the substrate and had diffused through the gold layer. While the eutectic temperature is $363{ }^{\circ} \mathrm{C}$, the interdiffusion of silicon and gold occurs at significantly lower temperatures. Si was observed to accumulate on the gold surface below $340{ }^{\circ} \mathrm{C}$ [18]. Although the thin film stack included a Ti adhesion layer, no trace of $\mathrm{Ti}$ was detected despite the fact that the bonding temperature exceeded the reaction temperature of $\mathrm{Ti}$ and $\mathrm{Au}$, which is around $200{ }^{\circ} \mathrm{C}$ [19], [20]. With only 10 $\mathrm{nm}$ of $\mathrm{Ti}$, it is possible that the $\mathrm{Ti}$ had completely reacted with either $\mathrm{Au}$ or $\mathrm{Si}$ (titanium silicides are relatively easy to form as well), preventing elemental Ti from diffusing through the Au layer. The presence of Si at the Au bonding surface will prevent bonding because Si hardens gold, which hampers the thermocompression process [10]. A diffusion barrier layer is thus needed. Silicon dioxide was chosen and a series of diffusion experiments were performed. Thermal oxides of varying thickness were grown, followed by standard photolithography and metal deposition processes. Annealing at $300{ }^{\circ} \mathrm{C}$ was carried out in a tube furnace under nitrogen, in order to duplicate the bonding conditions. Concentration of Si was obtained by multiplexing scans around the Au3 and $\mathrm{Si} 2$ Auger electron energy peaks. 


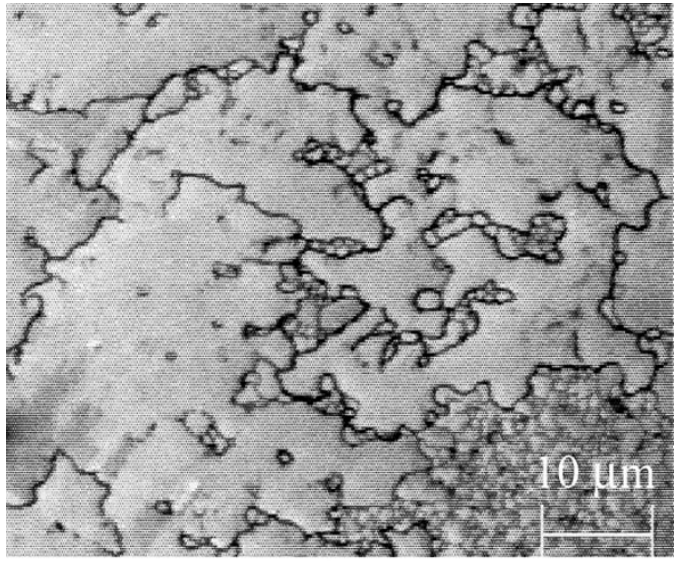

(a)

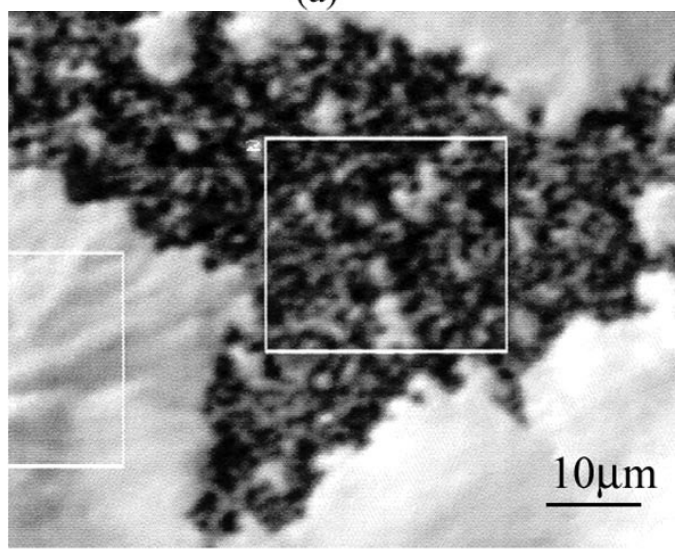

(b)

Fig. 3. (a) $\mathrm{SEM}$ of gold surface without $\mathrm{SiO}_{2}$ barrier layer after $10 \mathrm{~min}$ annealing at $300{ }^{\circ} \mathrm{C}$. Si (dark regions) decorates the grain boundaries. (b) Another specimen, annealed in air, after a few sputtering cycles to remove the surface carbon.

After 10 cycles of such scans, the ratio of the counts were taken. Table I shows that an oxide thickness above $1500 \AA$ 为 was sufficient to bar Si from reaching the surface. For the bonding experiments reported here, around $3000 \AA$ A-thick oxides were used.

In a bonding process that requires mating surfaces to come into atomic proximity, a smooth surface is preferred. The deposition process used an electron beam to melt and evaporate the solid source. Nonuniform and rapid heating of the source could cause the melt to bubble and push about the remaining solid particles. These particles could be ejected from the melt, resulting in spitting [21]. Micrometer diameter sized gold balls, as shown in Fig. 4, populated the surface and made them difficult to bond. To ensure a uniform melt prior to deposition, small amplitude rastering of the beam and a longer soaking period was implemented. In addition, the deposition rate was increased slowly (from $2 \AA / \mathrm{s}$ to $5 \AA / \mathrm{s}$ ) over the first $100 \mathrm{~nm}$ of the deposition. Most importantly, a tungsten inner liner was added to the graphite crucible. The presence of graphite has been correlated to spitting in the evaporation of $\mathrm{Ge}$ and $\mathrm{Cu}$ [22]. Instead of making modifications to the graphite crucible, gold spitting was solved by using a refractory tungsten liner, which is inert to gold. In addition, the wetting property of $\mathrm{Au}$ on $\mathrm{W}$ helps the melt to spread. This is an advantage as long as it is controlled and the melt does not overflow. Fig. 5 is an atomic force mi-
TABLE I

CONCENTRATION OF Si With VARYING $\mathrm{SiO}_{2}$ THICKNESS

\begin{tabular}{c|c|c|l}
\hline $\begin{array}{l}\text { Anneal } \\
\text { time [min] }\end{array}$ & $\begin{array}{l}\mathrm{SiO}_{2} \\
\text { thickness [̊] }\end{array}$ & Si [\%] & Note \\
\hline 10 & 0 & 35 & $\begin{array}{l}\text { Post 2 sputter } \\
\text { cycles }\end{array}$ \\
\hline 10 & 480 & 6 & \\
\hline 10 & 1550 & -- & \\
\hline 10 & 3030 & -- & \\
\hline 30 & 3030 & -- & \\
\hline 60 & 3030 & -- & \\
\hline
\end{tabular}

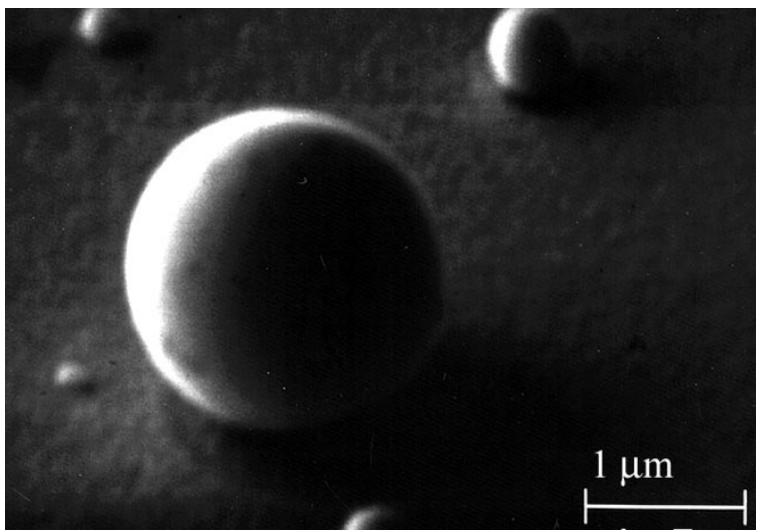

Fig. 4. SEM of Au balls on the surface due to source spitting.

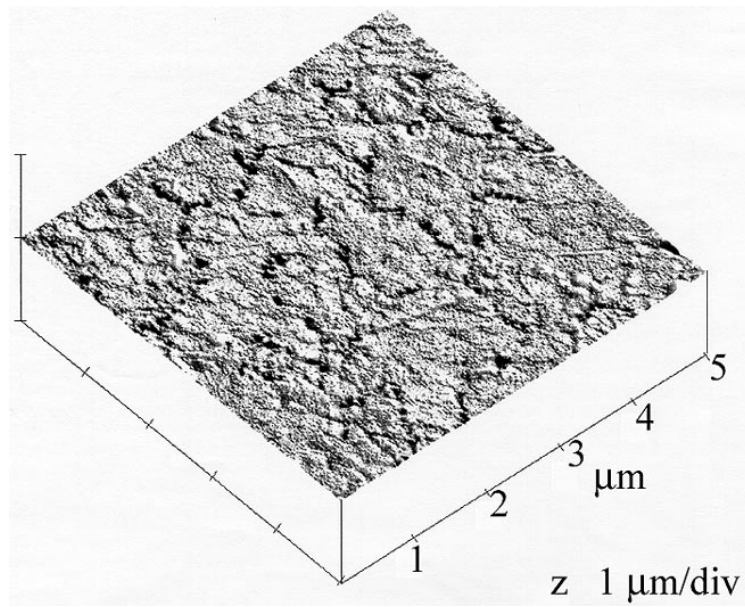

Fig. 5. AFM of Au surface after annealing at $300{ }^{\circ} \mathrm{C}$ for $10 \mathrm{~min}$. The substrate was plasma etched. rms roughness $=3.2 \mathrm{~nm}$.

croscopy (AFM) image of the film annealed at $300{ }^{\circ} \mathrm{C}$ for 10 $\mathrm{min}$. The rms surface roughness is $3.2 \mathrm{~nm}$. Since the surface was exposed to plasma during silicon etch, this may not represent the inherent roughness of the Au from the deposition process. Nevertheless, this order of surface roughness is sufficiently low to permit bonding. 

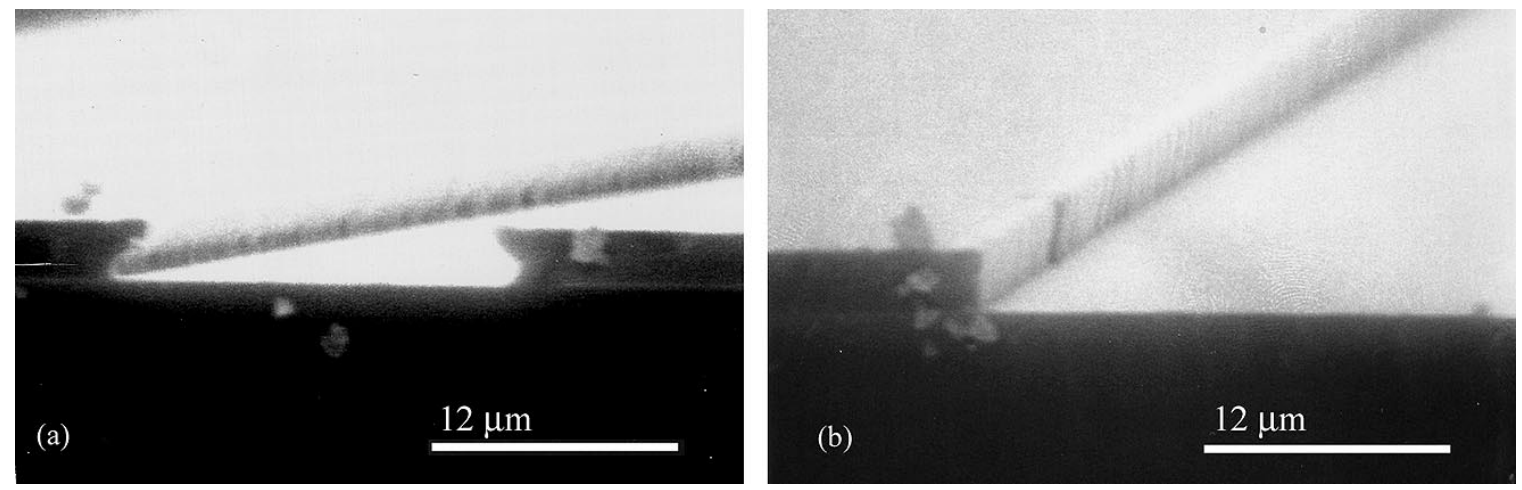

Fig. 6. Resist profile with 2 different exposure times. (a) Desired negative slope. (b) An additional $10 \mathrm{~s}$ exposure on a $320 \mathrm{~nm}$ wavelength aligner results in a nearly straight profile.

In addition to source spitting, undesirable bumps at the edges of the features could result from a suboptimal resist profile. For evaporation of relatively thick films, it is important for the resist to have a negative sloping profile. The photolithography process of AZ5214 resist is slightly different from a standard positive resist process: after the initial exposure with a mask, the wafers are baked for a short time and the whole wafer is blanket exposed. The process terminates with resist development, without the usual postbake. The slope of the resultant profile was found to be dictated by the duration of the initial exposure. Fig. 6 shows two profiles with a difference of $10 \mathrm{~s}$ in the exposure time on a $320 \mathrm{~nm}$ contact aligner.

The $\mathrm{KOH}$ etch step described in the process flow was necessitated by the mechanical testing procedure. As described by Charalambides et al., the test specimen has a notch placed in one of the substrates so that the interface is exposed and the crack propagates along the interface. However, the thin interface of the current specimen requires dicing with micrometer scale precision across the wafer. One alternative is to place the notch to within tens of microns of the interface, and then to load the specimen in a three point bending fixture to produce a precrack that runs through the remaining ligament in the DSP wafer, and even a short distance along the interface. To confine the precrack direction and to reduce mechanical interlocking during testing, two cuts were made at the notch: a deep, wide cut of approximately $220 \mu \mathrm{m}$ in width, followed by a $30 \mu \mathrm{m}$ wide cut that stops approximately $30 \mu \mathrm{m}$ away from the bond interface [17]. However, as illustrated in Fig. 7(a), the precracks were not always straight, resulting in mechanical interlocking during loading. The low toughness of the bond and the consequently low applied loads makes such interlocking a significant source of error. By implementing the $\mathrm{KOH}$ etch, the precracking step and resulting interlocking could be eliminated. The interface is exposed once the notch cut meets the bottom of the etched feature. An additional step that follows the $\mathrm{KOH}$ etch is the shallow etch. Thin resist such as AZ5214-E does not form conformal step coverage on wafers with deep etched features because the resist tends to recede from the edges of a deep etch. Metal would thus be deposited along the perimeter of the trench and would connect the metal lines horizontally at the edges of the notch. By having a shallow recess around the perimeter, the bonding features remain separated as required by the design.
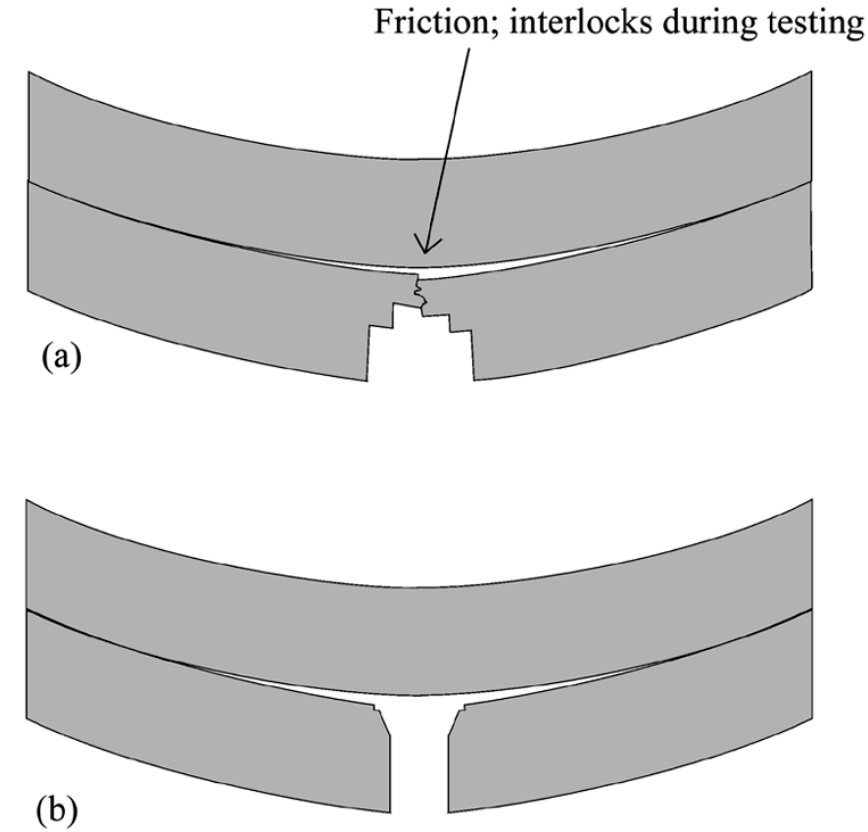

Fig. 7. Schematic of bending specimen in near notch region. (a) Notch made by successive diesaw cuts and three-point bending to induce a precrack. (b) Notch made by $\mathrm{KOH}$ etch. Possibility of mechanical interlocking during loading is eliminated.

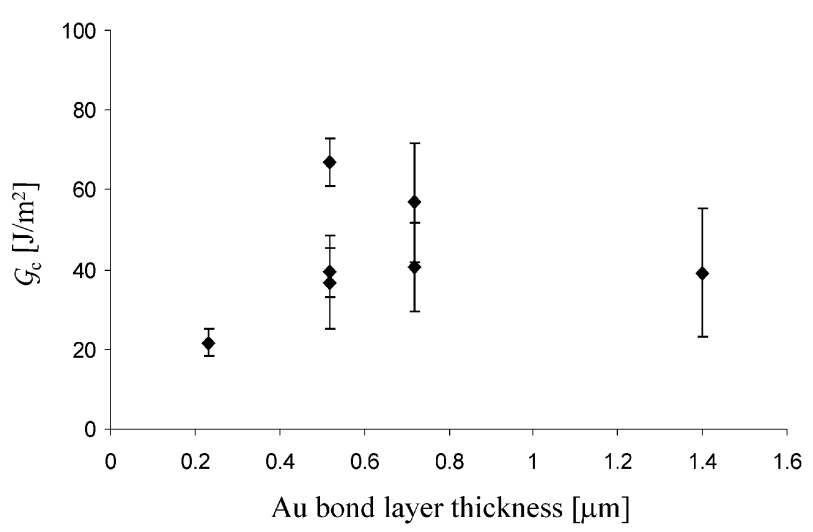

Fig. 8. Toughness, $\mathcal{G}_{c}$, as a function of bond layer thickness. Each data point represents measurements from four to seven specimens of the same wafer. 




(a)

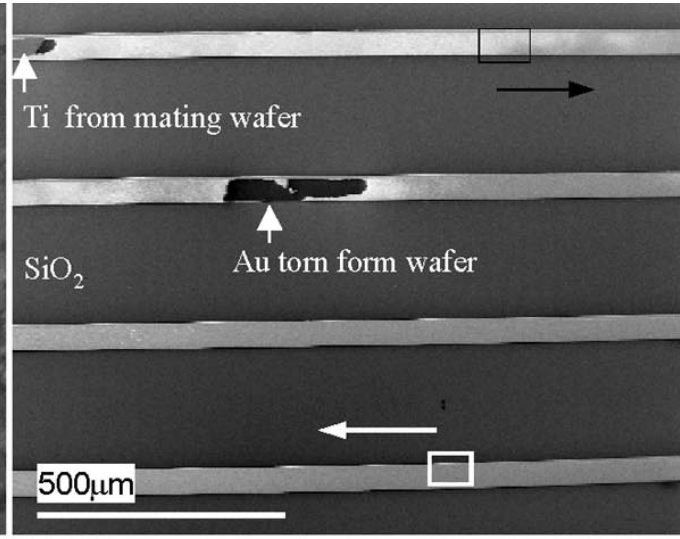

(b)

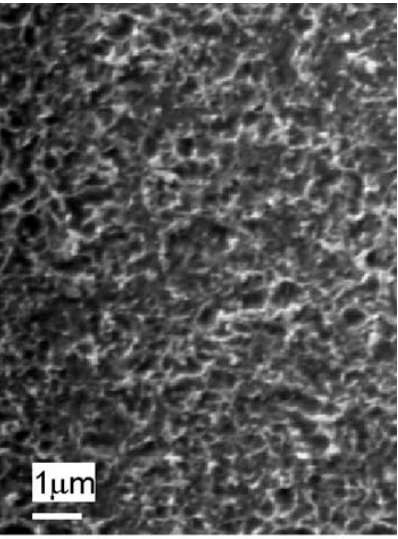

(c)

Fig. 9. SEM of fractured surfaces of a delaminated specimen with a $0.72 \mu \mathrm{m}$ bonding layer. (a) Magnified view of area with low plastic deformation. (b) Image of four lines showing variation in plastic deformation. Bright areas correspond to high plasticity. Adhesive failure is also observed. (c) Magnified view of area with more plasticity.

\section{B. Bond Toughness Results}

The toughness of a bonded interface can be viewed as composed of two components: elastic and plastic. The elastic part is basically the work of adhesion in the absence of any plastic dissipation. Studies of other materials systems by investigators using similar test techniques have found that the measured toughness in ductile bonds is a strong function of the thickness of the adhesive layer [23], [24]. A thinner adhesive layer is more severely constrained, which limits the plastic dissipation. The bond layer thickness range under study in the present work is rather narrow; therefore $\mathcal{G}_{c}$ was not shown to be a strong function of the bond layer thickness in Fig. 8. For specimens with a bonding layer greater than or equal to 0.52 $\mu \mathrm{m}, \mathcal{G}_{c}$ ranges from 37 to $67 \mathrm{~J} / \mathrm{m}^{2}$. In a $\mathrm{Cu}$ thin film system, such high $\mathcal{G}_{c}$ values corresponded to $\mathrm{Cu}$ thicknesses greater than $6 \mu \mathrm{m} \mathrm{[23].} \mathrm{The} \mathrm{yield} \mathrm{strength} \mathrm{of} \mathrm{Au}$ is less than that of $\mathrm{Cu}$; thus, more plastic dissipation is expected from $\mathrm{Au}$.

Energy dissipation has a larger plastic component when the bonds fail cohesively. ${ }^{1}$ Adhesive failure dominated in bonds formed by thinner films and transitioned into mostly cohesive failures in thicker films. However, a variation in the degree of plasticity was observed, not only between specimens, but within the same specimen. A SEM image of a delaminated specimen is shown in Fig. 9. By comparing the micrographs of the two boxed regions, Fig. 9(a) and (c), it is clear that more plastic energy was dissipated in the top two lines of Fig. 9(b). Depending on the amount of plasticity, the critical load at which delamination occurs could differ, resulting in the relatively large scatter of the $\mathcal{G}_{c}$ shown in Fig. 8. The source of this difference in plasticity is currently a subject of study. Variation in the fabrication process of nominally similar wafers and uniformity of the bond pressure distribution are both possible sources of this difference. The effect of process parameters on bond toughness will be the subject of a future paper.

\section{CONCLUSION}

The fabrication process for a wafer-level, low-temperature thermocompression bonds has been described. Since thermo-

\footnotetext{
${ }^{1}$ Cohesive failure refers to failure within the Au bonding layer while adhesive failure refers to failure at the $\mathrm{Ti}-\mathrm{SiO}_{2}$ interface.
}

compression relies on heat and pressure to bring two surfaces to close proximity for interatomic attraction to overcome surface asperities, a smooth surface is helpful in keeping the process temperature low. E-beam source spitting resulted in micrometer diameter sized $\mathrm{Au}$ on the surfaces, which rendered difficulty in bonding. The problem was solved by using a tungsten liner in addition to the graphite crucible. $\mathrm{A} \mathrm{SiO}_{2}$ diffusion barrier was used to prevent $\mathrm{Si}$ from diffusing to the Au surface at the bonding temperature. A four-point bend delamination technique was used to quantify the bond toughness, and the associated process steps that were required to prepare the test specimens properly were described. The critical strain energy release rate ranged between 22 to $67 \mathrm{~J} / \mathrm{m}^{2}$ and was not shown to be strongly associated with the gold bond layer thickness in the thickness range studied ( 0.23 to $1.4 \mu \mathrm{m})$.

\section{ACKNOWLEDGMENT}

The authors would like to thank K. Turner for his valuable assistance with the four-point bend setup and J. Wong for discussions regarding source spitting.

\section{REFERENCES}

[1] H. Reichl and V. Grosser, "Overview and development trends in the field of MEMS packaging," in Proc. 14th IEEE Int. Conf. on MEMS, 2001, pp. $1-5$.

[2] C. B. O’Neal, A. P. Malshe, S. B. Singh, W. D. Brown, and W. P. Eaton, "Challenges in the packaging of MEMS," in Proc. Int. Symp. on Advanced Packaging Materials, 1999, pp. 41-47.

[3] H. A. C. Tilmans, D. J. Van de Peer, and E. Beyne, "The indent reflow sealing (IRS) technique-A method for the fabrication of sealed cavities for MEMS devices," J. Microelectromech. Syst., vol. 9, pp. 206-217, 2000

[4] C. Y. Wang and C. C. Lee, "An eutectic bonding technology at a temperature below the eutectic point," in Proc. 42nd Electronic Components and Technology Conference, 1992, pp. 502-507.

[5] R. F. Tylecote, The Solid Phase Welding of Metals. New York: St. Martin's, 1968.

[6] D. Sparks, G. Queen, R. Weston, G. Woodward, M. Putty, L. Jordan, S. Zarabadi, and K. Jayakar, "Wafer-to-wafer bonding of nonplanarized MEMS surfaces using solder," J. Micromech. Microeng., vol. 11, pp. 630-634, 2001

[7] W. H. Ko, "Packaging of microfabricated devices and systems," Mater. Chem. Phys., vol. 42, pp. 169-175, 1995.

[8] J. L. Jellison, "Effect of surface contamination on the thermcompression bondability of gold," IEEE Trans. Parts, Hybrids Packag., vol. PHP-11, pp. 206-211, 1975. 
[9] L. W. Condra, J. J. Svitak, and A. W. Pense, "The high temperature deformation properties of gold and thermocompression bonding," IEEE Trans. Parts, Hybrids Packag., vol. PHP-11, pp. 290-296, 1975.

[10] Y. G. Kim, J. K. Pavuluri, J. R. White, I. J. Busch-Vishniac, and G. Y. Masada, "Thermocompression bonding effects on bump-pad adhesion," IEEE Trans. Comp., Packag., Manufact. Technol., vol. 18, pp. 192-199, 1995.

[11] B. K. Furman and S. G. Mita, "Gold-Gold (Au-Au) thermocompression (TC) bonding of very large arrays," in Proc. 42nd Electronic Components and Technology Conference, 1992, pp. 883-889.

[12] L. Parameswaran, "Silicon pressure sensor using wafer bonding technology," S.M. thesis, MIT, 1993.

[13] A. Drost, G. Klink, S. Scherbaum, and M. Feil, "Simultaneous fabrication of dielectric and electrical joints by wafer bonding," Proc. SPIE-Micromachined Devices and Components IV, pp. 62-71, 1998.

[14] A. Plossl and G. Krauter, "Wafer direct bonding: Tailoring adhesion between brittle materials," Mater. Sci. Eng., vol. R25, pp. 1-88, 1999.

[15] W. P. Maszara, G. Goetz, A. Caviglia, and J. B. McKitterick, "Bonding of silicon wafers for silicon-on-insulator," J. Appl. Phys., vol. 64, pp. 4943-4950, 1988

[16] P. G. Charalambides, J. Lund, A. G. Evans, and R. M. McMeeking, "A test specimen for determining the fracture resistance of bimaterial interfaces," J. Appl. Mech., vol. 56, pp. 77-82, 1989.

[17] C. H. Tsau, M. A. Schmidt, and S. M. Spearing, "Characterization of low temperature, wafer-level gold-gold thermocompression bonds," in Proc. Materials Science of Microelectromechanical Systems (MEMS) Devices II, 1999, pp. 171-176.

[18] K. Nakashima, M. Iwami, and A. Hiraki, "Low temperature diffusion of Au into $\mathrm{Si}$ in the Si(substrate)-Au(film) system," Thin Solid Films, vol. 25, pp. 423-430, 1975.

[19] H. Hieber, "Aging properties of gold layers with different adhesion layers," Thin Solid Films, vol. 37, pp. 335-343, 1976.

[20] K. Masahiro and S. Noboru, "Effects of temperature, thickness and atmosphere on mixing in Au-Ti bilayer thin films," J. Mater. Sci., vol. 28, pp. 5088-5091, 1993

[21] R. W. Berry, P. M. Hall, and M. T. Harris, Thin Film Technology: D. Van Nostrand, 1968

[22] M. L. Rappaport and B. Berkovitz, "A graphite crucible for spitting-free high rate e-gun evaporation of Ge," J. Vac. Sci. Technol., vol. 21, p. 102, 1982.

[23] M. Lane, R. H. Dauskardt, A. Vainchtein, and H. Gao, "Plasticity contributions to interface adhesion in thin-film interconnect structures," $J$. Mater. Res., vol. 15, pp. 2758-2769, 2000.

[24] I. E. Reimanis, B. J. Dalgleish, and A. G. Evans, "The fracture resistance of a model metal/ceramic interface," Acta Metall. Mater, vol. 39, pp. 3133-3141, 1991.

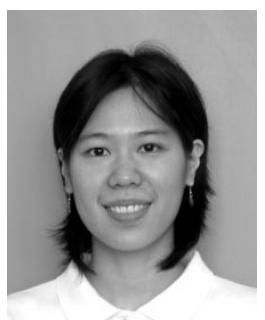

Christine H. Tsau received the S.B. degree in materials science and engineering from the Massachusetts Institute of Technology (MIT), Cambridge, in 1998 and is currently working toward the Ph.D. degree of the same department at MIT.

She is a Semiconductor Research Corporation Graduate Fellow.

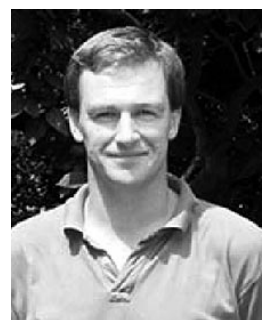

S. Mark Spearing received the Ph.D. degree from the Engineering Department of Cambridge University, Cambridge, U.K., in 1990.

From 1990 to 1992, he worked as a Research Engineer at the University of California at Santa Barbara producing analytical models for the failure of high-temperature ceramic materials and for Carborundum Microelectronics, where he was a member of the Electronic Packaging Technology Development Team from 1992 to 1994 . He is an Associate Professor of Aeronautics and Astronautics at the Massachusetts Institute of Technology (MIT), Cambridge, where he has been since 1994. His technical interests include materials and structural analysis and design of MEMS, development of wafer bonding-technologies, electronic packaging and advanced composites. Since 1995, he has been responsible for materials, structural design and packaging tasks of the MIT MicroEngine, MicroRocket, Micro-chemical power, and MicroHydraulic transducer projects as well as conducting cross-cutting underpinning technology development.

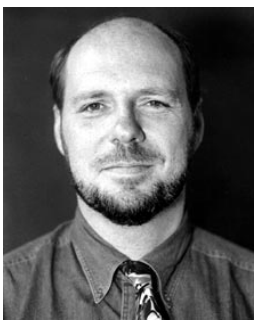

Martin A. Schmidt (S'88-M'85-SM'00) received the B.S. degree in electrical and computer engineering from Rensselaer Polytechnic Institute, Troy, NY, in 1981 and the S.M. and Ph.D. degrees in electrical engineering and computer science from the Massachusetts Institute of Technology (MIT), Cambridge, in 1983 and 1988, respectively. His Ph.D. research concerned microsensors for measurement of turbulent boundary layers.

In 1988, he joined the faculty of the Electrical Engineering and Computer Science Department, MIT, where he is currently a Professor of electrical engineering. He is also the Director of the Microsystems Technology Laboratories, MIT. His research interests are in microfabrication technologies for realization of micromechanical and biological reactors, micromachined turbine engines, and microactuators. He has served on the program committees for many of the major meetings in the microelectromechanical systems (MEMS) field and currently serves on the International Steering Committee for Solid-State Sensors and Actuators.

Dr. Schmidt was the recipient of the National Science Foundation Presidential Young Investigator Award and the Ruth and Joel Spira Teaching Award presented by MIT. 